\title{
REINTEGRO FAMILIAR Y REINTEGRO COMUNITARIO ${ }^{1}$
}

\section{Ángela María Quintero Velásquez²}

La familia se define como el lugar social del amor o como la unidad fundamental de convivencia entre un grupo de adultos y niños.

Humberto Maturana

\section{Introducción}

$\mathrm{E}$ l asunto objeto de este artículo es polémico, poco estudiado con rigor científico y con alta carga de subjetividad, en tanto cualquier persona se considera en condiciones de hablar al respecto. Por lo cual es un compromiso de los profesionales e entidades del sector, aportar en la construcción conceptual y estratégica del tema, ya sea como funcionario institucional (representante de una entidad), ciudadano raso, estudiante o académico, líder comunitario. En ningún momento la pretensión es agotar la temática, es co-crear unas directrices en la discusión, elaboración y abordaje integral.

La propuesta es aproximarse al Reintegro familiar y reintegro comunitario, en una perspectiva multidisciplinaria que comprometa todas los campos del saber, involucrados en el bienestar, especialmente las disciplinas sociales, humanas, jurídicas: psicología, trabajo

${ }^{1}$ Este trabajo esta basado en la ponencia Intervención con niñez y juventud en situación de especial vulnerabilidad, presentada en el $7^{\circ}$ Seminario Institucional de Ciudad Don Bosco, Medellín, 2002

${ }^{2}$ Docente del Departamento de Trabajo Social, Universidad de Antioquía, Medellín, Colombia. 
social, derecho, sociología, economía, pedagogía, teología, en cooperación con las ciencias naturales ó áreas de la salud. Ello implica también la integración de acciones de atención inmediata con enfoques preventivos, que preparen a las familias y comunidades para mitigar el impacto del fenómeno del abandono socio-familiar, que crece día a día.

La evolución del concepto es un cambio de paradigma, es asumir una visión distinta del papel del Estado y de las organizaciones encargadas de velar por la protección y crecimiento integral de cada uno de los miembros de la familia, fundamentalmente de los niños y jóvenes que dependen en todo sentido de los padres biológicos o figuras parentales. Esto es reconocer la importancia de la función básica de la familia en la formación de sus integrantes y su interacción con la sociedad. También es entender la necesaria convergencia que debe existir entre familia, estado y sociedad civil, para atender situaciones que quebrantan el normal desenvolvimiento de los individuos.

El modelo tradicional manejaba el criterio de la institucionalidad como una de las medidas esenciales para proteger y formar a los niños y jóvenes sin familia. La propuesta moderna habla de la desinstitucionalización, con el objetivo de que el medio natural del chico, que debiera ser la familia, sea quien acoja esta situación, no importando las condiciones difíciles que ella pueda tener. Un elemento adicional es establecer acciones programáticas que aminoren dichos riesgos y potencialicen una mejor calidad de vida. Son proyectos articulados, dirigidos a los niños y jóvenes y a la familia como un todo.

\section{Análisis socio-jurídico del Reintegro Familiar y Comunitario}

Las mutaciones paradigmáticas están acompañadas de cambios en la visión del mundo y en comprender los dilemas humanos de distintas maneras. Esto va más allá de enunciar de una o otra manera los referentes teóricos, es mas bien asumirlos con miradas y criterios, que le den un sentido alternativo. En cierta medida es fortalecer también la tolerancia a la diversidad, a la búsqueda de opciones personales, familiares y comunitarias, diferentes a las conocidas, a aceptar los errores y los procesos erróneos en el manejo de los afectos y de los desafectos y en las interacciones humanas.

Para el caso que nos convoca, esto es fundamental, en tanto fenómenos mundiales como la globalización, influyen a la familia y hacen que ella y cada uno de sus integrantes sea vulnerable a impo- 
siciones externas, sin los recursos suficientes para mantener distancia e identidad cultural y en algún momento de su evolución, desencadenen crisis severas que afecten su integridad. El escapar a situaciones conflictivas intra-familiares, sumado a presiones del grupo de pares (compañeros de escuela, vecinos, hermanos, etc) o imágenes de representación equivocadas (según programas de TV, películas, mensajes subliminales en comerciales), pueden generar ausencia del niño y joven de su hogar, asociadas con factores como abandono paterno-filial, fuga, desplazamiento forzoso.

Retomar algunos elementos teóricos sobre Familia son útiles al momento de comprender y abordar el Reintegro. A saber:

- La familia, atraviesa todos los procesos humanos: desde su origen el hombre, convive en algún tipo de familia. Con excepción de situaciones de los grupos poblaciones que nacen y crecen en ambientes diferentes a la familia: niños de la calle, huérfanos, desplazados por la violencia.

- En la época de transición secular: coexisten lo tradicional con lo moderno. Lo clásico con lo emergente. Esto es organizaciones y estructuras familiares tradicionales, con nuevas propuestas de funcionamiento familiar, individual y social.

- Convergencia: el mandato moderno exige alianzas, cooperación entre la familia, el estado y la sociedad civil. Responsabilidades compartidas, pero claramente definidas. Las políticas sectoriales en Familia no deben ser vistas como gastos, sino como inversión social.

- La Familia asume un protagonismo que la traslada de la esfera privada hacia la pública. Ya no está supeditada exclusivamente al criterio de otras instancias, sino que toma el mando de su funcionamiento, evolución y transmisión multi-generacional, y exige ser escuchada en las esferas privadas, gubernamentales y societales.

- Lo holístico requiere una mirada integral del individuo, la familia y la sociedad, donde no es posible desagregar los desarrollos específicos, que siempre deben estar articulados a lo general. (Quintero V, 2002) 
La familia es el medio natural para el crecimiento y bienestar de los infantes, en cumplimiento de la función psico-afectiva que está demostrado históricamente es intransferible a otra institución social. Independiente de que existan crisis y conflictos, resueltos o no en mayor o menor grado, la familia genera vínculos emocionales y estructurales, esas son las realidades familiares que tiene que asumir cada sujeto.

Es prioritaria la reflexión sobre la diversidad familiar que ofrece este siglo de la incertidumbre y que permea la estructura, función y evolución de la familia como el máximo de los sistemas sociales y el grupo primario por excelencia. No puede hablarse de un arreglo relevante, sino de una gran variedad, con matices que oscilan de las tipologías tradicionales, a las de nuevo tipo y a otras formas de convivencia. Ninguna de ellas es inmune a la posibilidad de sufrir el abandono/ausencia de un niño y joven, pero si existen condiciones socio-económicas y políticas asociadas con el fenómeno, independiente de la organización familiar en que ocurra.

Un rastreo empírico del fenómeno evidencia que la mayoría de los casos que ameritan Reintegro, las tipologías familiares son extensas y ampliadas, presentes en los estratos uno y dos, en barrios con altos índices de hacinamiento, violencia de todo tipo y precariedad en la asistencia gubernamental en todas sus formas. Fortalezas de estas familias son los lazos de solidaridad y cooperación mutua, que se activan para recibir a un miembro ausente y propiciar un reencuadre en lo estructural y funcional. Las redes socio-familiares, formales e informales, y el sentido de la ayuda mutua, también operan como elementos altamente positivos y potenciadores de procesos de adaptación y recomposición.

En las últimas décadas, el Reintegro es un asunto de competencia estatal y jurídica, por cuanto está asociado con violencia familiar y de orden público (léase guerrilla-milicianos, común, narcoterrorismo, paramilitares), que exigen la presencia de la ley y posee una jurisdicción institucional para garantizar la integridad de los miembros más vulnerables de la familia y de la comunidad en general. Esto en alusión a las facultades expresadas en el Código del Menor (1989) y en la Ley de Violencia Intrafamiliar (Leyes 294 de 1996 y 275 del 2000), que permiten que el espacio tradicional, íntimo y preservado de la familia ya sea de competencia de las instancias recomendadas, comisarías, juzgados de familia, Instituto Colombiano de Bienestar Familiar (entidad estatal rectora encargada 
de atender la familia y el menor), inspecciones, organizaciones no gubernamentales, etc para evitar, mitigar o sancionar atropellos hacia los niños y jóvenes.

El asociar el abandono o escape del hogar al maltrato y las diversas manifestaciones de la Violencia, establecen la necesidad de conocer las implicaciones y alcances de la normatividad al respecto. Es perentorio entender además la Violencia como una forma de socialización, por lo cual individuos que han sido objeto de ella, tienden a reproducirla en sus nuevas relaciones de pareja y familiares. Esto exige acciones educativas y terapéuticas a corto y mediano alcance, que permitan desaprender la violencia y asumir la diferencia y la contradicción como un elemento propio de la condición humana.

Por ello el Reintegro Familiar y Comunitario, incumbe a todos y a todas, pues ya sea que el niño o joven haya estado institucionalizado, o deambulando en la calle o viviendo temporalmente bajo otra forma, se cumple un proceso de adaptación que demanda los recursos internos de los involucrados y los ajustes para continuar con los proyectos de vida individuales y colectivos. El apoyo profesional y organizacional en todo el procedimiento es básico, permite a la familia y comunidad, asumir otras oportunidades y formas de convivencia.

La exclusión, pobreza e incumplimiento de las necesidad básicas implícitas en el tema expuesto, se evidencia en las políticas sociales en Familia. Reconocida por la ciudadanía, es su carácter coyuntural, remedial, inmediatista y político, atendiendo eventos inminentes de impacto socio-económico, pero que no tienen continuidad temporera-espacial, ni gubernamental. Expresión de ello, es el papel de las ONG e instituciones del sector, que cada día ven más recortados sus recursos y la necesaria financiación estatal.

Esto exigiría acciones concretas del Estado, que refrenden el Reintegro familiar y comunitario en condiciones dignas: programas oficiales de empleos estables, con cobertura de seguridad social, para garantizar que los padres o figuras parentales cumplan adecuadamente su función de proveedores. También requeriría fomento a las micro empresas y a las empresas familiares, como alternativas de subsistencia y de cohesión familiar; garantía de acceso a la educación formal y capacitación técnica, que eleven el nivel cultural y la participación social; promoción de los derechos y deberes ciudadanos; y atención y prevención de las disfunciones individuales, familiares y comunitarias. 
¿Qué nos sugieren los términos? De inmediato hacemos referencia a niños y jóvenes abandonados, sin núcleo familiar, maltratados, abusados o violentados, deambulando por las calles de las grandes y medianas ciudades, donde es más evidente el hecho. Expuestos a la intemperie, con insatisfacción de sus necesidades básicas, en lo instrumental y en lo afectivo, con patrones de socialización basados en actos transgresores de las normas sociales, la ley del mas fuerte, consumo de sustancias tóxicas, promiscuidad sexual... En fin un panorama desalentador, pero que con frecuencia tampoco es así.

No obstante, niños y jóvenes privados de su medio familiar natural, son más vulnerables a riesgos que alteren el proceso normal de su desarrollo y no es la condición ideal, máxime cuando existe un Estado ausente o laxo en la protección integral de ellos.

Un rápido y fragmentario recorrido por algunos sitios de la región, evidencia que las expresiones en mención están asociados con fenómenos como: violencia familiar, social y política, derecho y legislación de familia (patria potestad, custodia, alimentos), pobreza, inequidad, exclusión, instituciones de protección, niños de la calle, menor trabajador, desplazamiento forzoso, migración.

Los aportes contemporáneos, desde las ciencias jurídicas y sociales, desarrollan el concepto de El derecho del niño a vivir en su familia biológica, expresado en afirmaciones como las siguientes: (Monesterolo, 2000.)

- La convención sobre los derechos del niño, extiende los derechos de los progenitores a miembros de la familia ampliada a fin de favorecer la permanencia del niño en su familia de origen cuando sus padres están en imposibilidad de atenderlos.

- ...el mejor ejercicio de la ciudadanía del niño se da en el ámbito de la familia

- La convención [sobre los derechos del niño], así mismo declara que los Estados Partes se comprometen a asegurar al niño la protección y el cuidado que sean necesarios para su bienestar, teniendo en cuenta los derechos y los deberes de los padres y para este fin tomarán todas las medidas legislativas y administrativas adecuadas....constituye un deber jurídico del Estado el desarrollar las acciones necesarias para apoyar a la familia en el ejercicio de estos roles. 
- El niño y el adolescente tienen derecho a participar de esta convivencia comunitaria como espacio que permita la multiplicación de las relaciones de convivencia, de relaciones interpersonales y que constituyen un recurso vital para su crecimiento y desarrollo.

- El derecho a la identidad se refiere tanto a la identidad individual como cultural.

Monesterolo (2000) también señala que la Convención para la protección delos niños y la cooperación en materia de adopción internacional, más conocida como la Convención de la Haya, en su preámbulo recuerda la prioridad con que cada Estado debe tomar medidas apropiadas que permitan la permanencia de sus niños en su familia de origen. De igual forma, Kaluf (1997) plantea que las políticas familiares orientadas al desarrollo de las relaciones interpersonales y a la satisfacción de las necesidades psico-socio-espirituales permite ofrecer bienestar y mejora la calidad de vida en términos no materiales.

\section{Estrategias de atención en los programas de Reintegro.}

El medio natural para cualquier ciudadano es su familia, independientemente de su estructura y funcionamiento. Solamente en aquellos casos en que esté afectada la integridad física y emocional en el medio familiar, el Estado tiene competencia para mediar en el asunto y protegerlo, en lo posible transitoriamente, mientras se instituyen acciones integrales que involucren a los niños y jóvenes y demás integrantes de la familia.

El escenario original para restablecer la situación de abandono, exclusión, violencia, es la familia en cualquiera de estas denominaciones: de origen o biológica, extensa, ampliada, por adopción (que asume los mismos derechos y deberes) y en casos demasiado complejos, familias amigas y hogares o familias sustitutas, financiadas y controladas por el Estado.

Para asumir de manera más real y propositiva el Reintegro familiar y comunitario es menester considerar:

El Enfoque de Convergencia: los compromisos compartidos entre familia, sociedad y estado, a través del diseño, ejecución y segui- 
miento de acciones interinstitucionales, interdisciplinarias e intersectoriales, que impliquen concertación, cooperación y alianzas estratégicas.

La ausencia del niño y joven, cualquiera fuera su causa, no es el principal problema de la familia, sino que expresa una disfuncionalidad (síntoma en el sentido clínico), por lo cual se requiere un trabajo con todo el sistema familiar, con el ánimo no de hallar culpables, sino de que cada uno asuma la responsabilidad en el asunto, tanto en su etiología como en sus propuestas de enfrentamiento.

Las propuestas metodológicas útiles en el proceso de Reintegro Familiar y Comunitario son:

\section{Grupos de Ayuda Mutua-GAM.}

Es la activación de los dispositivos comunitarios para apoyar y prevenir la presencia del evento. Son pequeños grupos formados por personas a las que afecta un problema común. Su objetivo es la prestación de servicios materiales o emocionales, para atender el individuo, la familia y la comunidad. Los principios que lo rigen son: cooperación, igualdad y ayuda mutua. La característica básica es de una organización sin intervención de los profesionales, en un primer momento de la vida grupal si es necesario su aporte metodológico y conceptual, pero la esencia de los GAM es adquirir una dinámica y funcionamiento autónomo, que como tal se ajustan a los contextos específicos donde operan. Los profesionales son concebidos como un canal que legitima el grupo e intervienen solo a solicitud de éste.

Algunas de las funciones de los GAM son: intercambio de experiencias, realización de actividades recreativas, prestación de servicios directos y constituirse en grupos de presión social y apoyo emocional. Están basados en la solidaridad y apoyo social para alcanzar objetivos, que de forma individual seria imposible.

Los GAM son diferentes del Modelo de Autoyuda, ya que implican una "mediación técnica". Estos grupos conllevan siempre una actividad planificada, por lo tanto requiere una propuesta claramente explicitada para efectuar la convocatoria. La misma podrá ser enriquecida y modificada por el propio grupo. La mediación técnica alude a la presencia de un profesional o equipo profesional, que asume el rol de coordinación y favorezca el desarrollo de las interacciones." (Eroles, 1998). Esto quiere decir que los supuestos 
de trabajo pueden ser los mismos pero el procedimiento operativo difiere en cuanto la capacidad de convocatoria de las comunidades y familias; y a su capacidad de autogestión, que las exime de la presencia de los profesionales como facilitadores de procesos de cambio.

\section{Redes socio-familiares}

Este mecanismo informal de la solidaridad, la cooperación y el sentido gregario del ser humano opera como un importante factor en el Reintegro y coadyuva en los inevitables y con frecuencia dolorosos ajustes que tienen que asumir los diversos sistemas humanos involucrados. Puede tomarse de dos maneras:

\section{La Red como estrategia de trabajo socio-familiar.}

La red es entendida como una importante estrategia en la estructuración de la calidad de vida del individuo y su familia, que recoge varios de sus elementos tradicionales y se proyecta hacia la modernización que exige el tercer milenio para los programas socio-familiares. La esencia del concepto, está asociada a los patrones de ayuda mutua y es intrínseca a la condición gregaria del ser humano y al vínculo societario

Su práctica empírica, basada en la cohesión, la solidaridad, la asociación ha dado paso a propuestas institucionales y estatales para enfrentar determinadas situaciones; lo que obviamente marca una gran diferencia con la naturaleza de la red. (Vr.gr Red de Prevención de la Violencia Familiar, Red de Atención al Maltrato Infantil, etc).

Una de las características básicas de la red es la colaboración e interacción socio-familiar, donde prima lo afectivo y emocional y el intercambio mutuo de acciones, a través de los procesos comunicacionales tanto analógicos (no verbales) como digitales (verbales).

\section{Red de solidaridad socio-familiar como programa institucional.}

Las funciones básicas que cumplen con las familias son: ser fuente de apoyo, brindar protección psico-afectiva y sanitaria y ser soporte en los momentos de conflicto y crisis. Esta demostrado el efecto poderoso que representan como auxiliares de los sistemas de Seguridad Social, pues cubren situaciones y disfunciones no atendidas por el Estado. 
En un contexto más amplio las redes buscan socializar el conocimiento y las experiencias. Esto es aplicable en los Grupos Psicoeducativos y Grupos de Ayuda Mutua-GAM o autoayuda, que con matices, apuntan a brindar apoyo e información a las familias que se organizan en torno a problemas comunes.

\section{La Resiliencia}

La asombrosa capacidad humana de enfrentar la adversidad y construir proyectos alternativos de vida, emerge con fuerza en el Reintegro y es necesario tenerla en cuenta en los programas preventivos y terapéuticos. La Resiliencia es un elemento, que si bien ha acompañado el desarrollo de la humanidad, se conceptúa y presenta a la comunidad científica en las últimas décadas. Como concepto y estrategia programática, es aplicada en el campo de la Familia, siendo útil para su estudio, investigación, procesos de adaptación y construcción de nuevas propuestas de intervención, acordes con el cambio de paradigma y las exigencias del tercer milenio.

Las instituciones y el Estado deben promover proyectos permanentes de activación de la resiliencia, en todos los grupos poblacionales, para evitar y minimizar el impacto de fenómenos como el referido. Los niños y jóvenes, poseen recursos internos e insospechados para sobrellevar, las dificultades intra y extra-familiares, y el reconocimiento de estos facilita el ajuste y adaptación del proceso de Reintegro. Ello requiere identificar los mecanismos individuales, familiares y comunitarios que permiten la activación de Resiliencia, en el plano personal y profesional y comprender la misma en una perspectiva integral y preventivo-promocional.

La conceptuación interdisciplinaria de la Resiliencia, en tanto es un vocablo originado en la ciencias naturales, pero aplicado y desarrollado en varias áreas el saber, es válido en el Reintegro Familiar y Comunitario, por resaltar de manera científica la importancia del vínculo afectivo, de la cultura, de la identidad social, de la cosmogonía en la formación del ser humano y en las opciones innatas no sólo de superar la adversidad, sino de emerger y asumir positivamente la crisis o evento traumático.

En razón de lo cual la Resiliencia está asociada con las Formas Alternativas de Afrontar el Conflicto socio-familiar (presentes en todos los países de occidente bajo diferentes denominaciones), pues 
su aplicación requiere el reconocimiento y potenciación de los recursos internos para manejar y enfrentar el estrés, crisis y conflictos, inherentes a todos los sistemas humanos, lo cual es fundamental en la Resiliencia. Estos procedimientos alternos se pueden ilustrar en la Constitución Colombiana de 1991 y recientes medidas legislativas, que permiten a los profesionales, comunidades y cualquier ciudadano o ciudadana, afrontar las dificultades en cualquier tipo de relaciones, sin necesidad de recurrir a la ineficiente justicia ordinaria. La más conocida es la Conciliación y en otros países ya se legisla sobre la Mediación familiar.

Pasos para lograr el Reintegro de los niños a sus familias.

Considerando que el niño y joven ha estado durante algún tiempo institucionalizado, es factible retomar el siguiente modelo a seguir en el proceso del Reintegro:

a. Conocer: ... las partes van reconociendo situaciones que están presentes en la forma de relacionarse. No es pues sólo conocer para el profesional tomar decisiones desde él; es un conocer puesto al servicio de los niños y sus familias, a fin de que sean ellos quienes descubran y encuentren sentido a los que ha venido ocurriendo en sus vidas.

b. Toma de decisión: Si la institución concluye beneficios en el reintegro y el niño o joven no lo acepta, debe realizarse un proceso de trabajo tendiente a lograr un cambio de posición; no creo en una imposición. Una negativa del lado de la familia significa la inexistencia de su deseo por el niño y no haría nada por cambiarle su posición, su decisión.

c. Preparación para el retorno: Esta cercanía desde los contactos e intervenciones, posibilita a la familia enterarse de quién continúa siendo el niño, despojándose de esa idea de cambio "mágico" que según ellos logra la institución. También permite al niño o joven sentirse de nuevo como actúa su familia y que ha transformado.. Las manifestaciones de miedos, dudas, expectativas, promesas y compromisos permiten entender qué quiere el uno del otro y lo lejos ó cerca que está de alcanzarlo. 
d. Reintegro: ...no es un momento, es un proceso, la duración la da la particularidad de cada caso. (Jiménez, Teresita. Ciudad Don Bosco: 1998)

Lo mencionado ratifica la necesidad de que la propuesta contemporánea del Reintegro Familiar y Comunitario, a tono con el paradigma del tercer milenio, sea estudiada y abordada con rigor conceptual y metodológico por los profesionales, los organismos gubernamentales y no gubernamentales y por la sociedad civil en general, generando programas tanto de atención directa como preventivos, que involucren todas las áreas del saber y los sectores del desarrollo humano.

Ello implica asumir una visión diferente del mundo, que trascienda el asistencialismo y potencie los recursos familiares y comunitarios, con el fin de optimizar la calidad de vida y comprometer acciones conjuntas, que reivindiquen la función de protección pisoafectiva que ha brindado durante siglos la familia a sus integrantes en su proceso vital, permitiendo su maduración y socialización individual, grupal y societal.

\section{Bibliografía}

Arriagada, Irma (2001). ¿Familias vulnerables o vulnerabilidad de las familias? Ponencia presentada en el Seminario Internacional Las diferentes expresiones de la vulnerabilidad social en América Latina y el Caribe: conceptos, medición y políticas. Santiago de Chile, DDS-CEPAL. CELADE, 20 -21 de junio.

Centro Latinoamericano de Trabajo Social-Celats (2000-01). La Intervención Social con Familias en los Nuevos Escenarios. Módulos I-II-III-IV-V. Curso de Educación a Distancia. Lima: Lerma Gómez eirl.

Donoso, José Ignacio (2000). La desinstitucionalización. Ponencia presentada en el Primer Congreso Nacional, Para cada niño una familia. Guayaquil: INFA, UNICEF, Ministerio de Bienestar Social. 
Gilbert de Babra, María (2000). Alternativas de atención a niños privados del medio familiar. Ponencia presentada en el Primer Congreso Nacional, Para cada niño una familia. Guayaquil: INFA, UNICEF, Ministerio de Bienestar Social.

Jiménez, Teresita (1998). La Familia en el entorno social de la niñez en la protección. $4^{\circ}$ Seminario Institucional de Ciudad Don Bosco, Medellín.

Kaluf F, Cecilia y Amuras P, Marta (1997). Políticas públicas y familia en América Latina y el Caribe. Ponencia presentada en la IV Conferencia Iberoamericana sobre Familia. Cartagena de Indias: ICBF, Universidad Externado de Colombia, Rencif.

Monesterolo de Baquero, Adriana (2000). El Derecho del niño a vivir en su familia biológica. Ponencia presentada en el Primer Congreso Nacional, Para cada niño una familia. Guayaquil: INFA, UNICEF, Ministerio de Bienestar Social.

Quintero Velásquez, Ángela María (2002). Escenarios contemporáneos de la familia. AGORA, 2, Universidad San Buenaventura.

Quintero Velásquez, Ángela María (2000). Formas Alternativas de Enfrentar el Conflicto socio-familiar. Buenos Aires: Lumen.

Quintero Velásquez, Ángela María (1997). Trabajo Social y Procesos Familiares. Buenos Aires: Lumen/Hvmanitas. 
